University of Wollongong

Research Online

Faculty of Engineering and Information

Faculty of Engineering and Information

Sciences - Papers: Part A

Sciences

$1-1-2016$

Delivering sustainable building projects - challenges, reality and success

Haleh Rasekh

University of Wollongong, hr599@uowmail.edu.au

Timothy J. McCarthy

University of Wollongong, timmc@uow.edu.au

Follow this and additional works at: https://ro.uow.edu.au/eispapers

Part of the Engineering Commons, and the Science and Technology Studies Commons

Research Online is the open access institutional repository for the University of Wollongong. For further information contact the UOW Library: research-pubs@uow.edu.au 


\title{
Delivering sustainable building projects - challenges, reality and success
}

\begin{abstract}
This research concerns the delivery of sustainable building projects. These projects are defined as those which either attempt to achieve green ratings or are claimed to address certain sustainability issues. A key focus is to examine how the client's vision for sustainability is achieved or compromised by the practicality of construction. Two sustainability rating systems, the Australian Green Star and the Living Building Challenge from the U.S. are discussed. This research examines two projects; one university multipurpose building (SMART Infrastructure Facility); and an advanced research facility, the Sustainable Buildings Research Centre (SBRC). The methodology used is semi-structured interviews of key participants and stakeholders for the two university building. The outcome of this research indicates that environmental rating systems are useful tools to construct reasonably sustainable buildings. Many interviewees, however, believe that for their next projects the concern would be to continue to construct sustainable buildings but not necessarily by following the strict criteria and reporting requirements of the environmental rating system.
\end{abstract}

\section{Keywords}

success, reality, delivering, challenges, -, projects, building, sustainable

Disciplines

Engineering | Science and Technology Studies

\section{Publication Details}

Rasekh, H. \& McCarthy, T. J. (2016). Delivering sustainable building projects - challenges, reality and success. Journal of Green Building, 11 (3), 143-161. 


\title{
Delivering sustainable building projects - challenges, reality and success
}

\author{
Haleh Rasekh $^{(1)}$, Timothy J McCarthy ${ }^{(2)}$ \\ 1. Doctoral student, 2. Professor of Civil Engineering
}

School of Civil, Mining and Environmental Engineering University of Wollongong, Wollongong, Australia 2522

\begin{abstract}
This research concerns the delivery of sustainable building projects. These projects are defined as those which either attempt to achieve green ratings or are claimed to address certain sustainability issues. A key focus is to examine how the client's vision for sustainability is achieved or compromised by the practicality of construction. Two sustainability rating systems, the Australian Green Star and the Living Building Challenge from the U.S. are discussed.
\end{abstract}

This research examines two projects; one university multipurpose building (SMART Infrastructure Facility); and an advanced research facility, the Sustainable Buildings Research Centre (SBRC). The methodology used is semi-structured interviews of key participants and stakeholders for the two university building.

The outcome of this research indicates that environmental rating systems are useful tools to construct reasonably sustainable buildings. Many interviewees, however, believe that for their next projects the concern would be to continue to construct sustainable buildings but not necessarily by following the strict criteria and reporting requirements of the environmental rating system.

Key words: Sustainable development; Sustainable building; Green Star; Living Building Challenge

\section{Introduction}

\subsection{Environmental impacts of buildings}

The most important impacts of buildings and building products are global warming, resource depletion, poor indoor air quality, and ecological toxicity. The building sector contributes a quarter of Australia's total greenhouse emissions and this country has the highest per capita greenhouse emissions of all the major developed countries (Bremner et al., 2010). The global $\mathrm{CO}_{2}$ emission in 2010 was $33.6 \times 10^{9}$ tonnes, representing 4.9 tonnes per capita. The per capita value was 16.9 tonnes for Australia which is the $12^{\text {th }}$ highest in the world 
(The World Bank Group, 2014). Scheuer et al., (2003) examined the environmental impacts of commercial buildings during their life cycles including resource consumption, air pollution, and solid waste generation. They estimated that $94.1 \%$ of the initial embodied energy and $93.6 \%$ of the life cycle embodied energy were from materials. Steel, cement, and sand were the biggest contributors to the primary energy in the building because of the large amount used. Haapio \& Viitaniemi (2008) analysed the environmental impact of different building materials over the life time of the building by assessing 78 single-family houses to find out which building material was the most eco-friendly. Wooden window frames had a less negative environmental impact than aluminium frames. The comparison of roofs made of steel, concrete and clay tiles indicated that steel and concrete are better materials. Steel contributes more to water pollution than concrete but other environmental impacts such as global warming and air pollution are lower.

\subsection{Sustainable development}

A sustainable building is defined as a building with minimum negative impacts on the natural surroundings, materials and resources. This kind of building does not deny human needs because it considers human existence to be part of nature; rather, it is constructed in line with the idea that humanity can exist, multiply, build, and prosper with nature and the earth's natural processes without damaging the long term habitability of the planet (Wilkinson et al., 2014).

Sustainable buildings reduce the destruction of natural areas, habitats, and biodiversity, air pollution, water pollution, solid waste and they lower operating, maintenance, and environmental costs. The use of natural resources is minimised because renewable energy sources are used instead of non-renewable natural resources such as land, water, and construction materials. This kind of building minimises negative outdoor environmental impacts such as greenhouse gases, global warming and acid rain as well as maximising the quality of the indoor environment and thermal comfort. A sustainable building also generates better long-term economic value and greater human satisfaction and productivity (Garzone, 2006; Kibert, 2012).

The World Commission on Environment in 1987 defined sustainable development as a development which 'meets the needs and aspirations of the present without compromising the ability to meet those of the future' (Brundtland, 1987).

Coimbra \& Almeida (2013) showed that a sustainable building needed $60 \%$ less energy and $70 \%$ less natural gas per square metre than a traditional building. Baird \& Field (2013) did further research on the thermal 
comfort conditions in 11 sustainable commercial and institutional buildings in different parts of the world. This research showed that the sustainable buildings performed well in both summer and winter. The results from these studies show that constructing sustainable buildings is an efficient way to decrease our negative environmental impact.

\subsection{Environmental rating systems}

The most widely used sustainable building evaluation tools are BREEAM, developed in the UK and LEED, developed in the USA (Nguyen \& Atlan, 2011). Most developed countries have their own versions of these tools. In Australia, Green Star has been in use for over a decade. A relatively new scheme, called the Living Building Challenge (LBC), has been developed by the International Living Future Institute and is being used more and more internationally (International Living Future Institute, 2010). In this paper, we discuss the Green Star rating system as it is the most widely used assessment tool in Australia and also the LBC as an alternative.

\subsubsection{The Green Star environmental rating system}

The Green Star rating system was launched by the Green Building Council of Australia (GBCA) in 2003 (Green Building Council of Australia, 2014). The key objectives were to drive the transition of the Australian property industry towards:

- Sustainability by promoting green building programs, technologies, design practices, and operations.

- Integration of green building initiatives into mainstream building design, construction, and operation.

Assessment criteria (see Figure 1) are computed in eight categories with a maximum of 100 points. An additional 5 points are awarded for innovation (Green Building Council of Australia, 2014). 


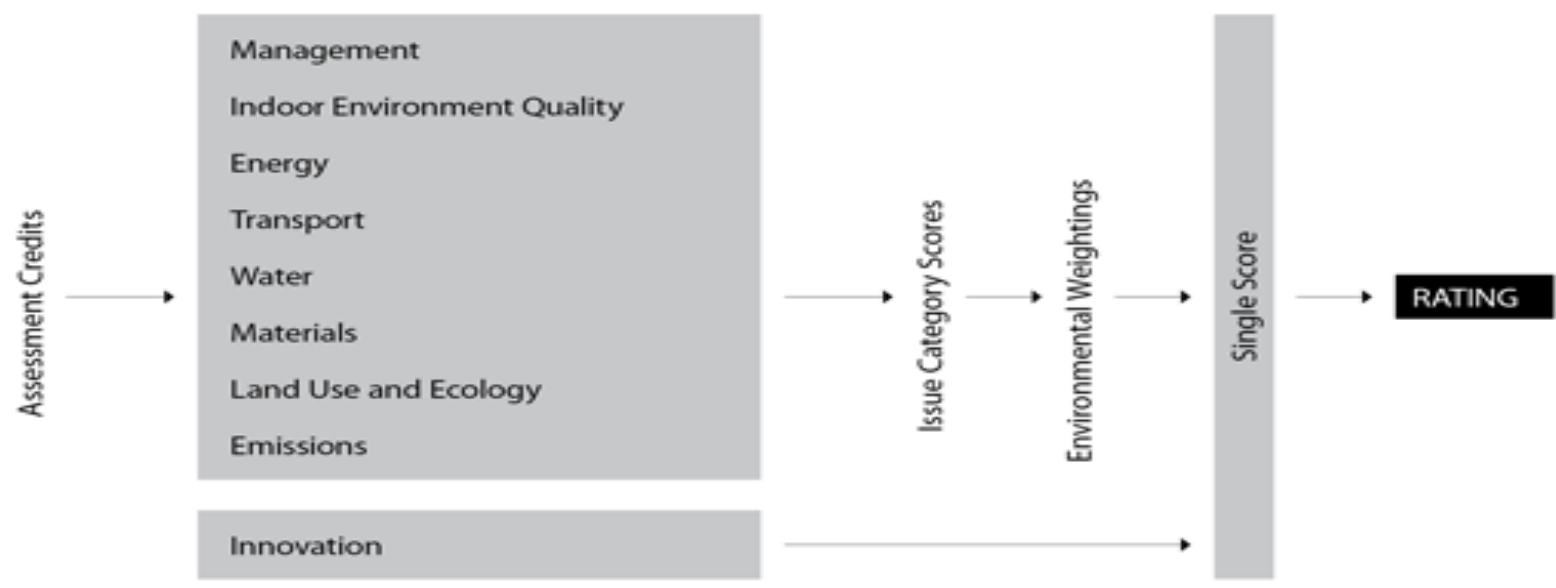

Figure 1: Categories and the processes of the Green Star rating system

(Green Building Council of Australia, 2014)

The Green Star rating achieved depends on the overall score. Buildings can achieve a Green Star certificate only at Four, Five or Six Stars as shown in Table 1.

Table 1: Green Star rating points (Green Building Council of Australia, 2014)

\begin{tabular}{|c|c|}
\hline Green Star rating & Points \\
\hline Four Star & $45-59$ pts Best Practice \\
\hline Five Star & $60-74$ pts Australian Excellence \\
\hline Six Star & $75+$ pts World Leadership \\
\hline
\end{tabular}

As can be seen in Table 2, the number of projects certified and registered by the GBCA has grown steadily from 2003 to 2012 (Romilly, 2012). Of the 515 buildings certified, 54 achieved 6 stars and 201 received 5 stars. From this data we see that approximately 10 percent of registered projects receive 6 stars while 40 per cent receive 5 stars. The number of registrations peaked in 2008 and dropped off with the impacts of the global financial slowdown taking effect. The annual number of registrations is in the range 100-200 (Green Building Council of Australia, 2013). 
Table 2: Number of projects certified and registered by the Green Star from 2003 to 2013 (Romilly, 2012)

\begin{tabular}{|c|c|c|}
\hline year & Certifications (Total) & Registrations (Year) \\
\hline 2003 & 0 & 4 \\
\hline 2004 & 1 & 21 \\
\hline 2005 & 8 & 25 \\
\hline 2006 & 23 & 257 \\
\hline 2007 & 41 & 263 \\
\hline 2008 & 124 & 117 \\
\hline 2009 & 212 & 148 \\
\hline 2010 & 292 & 146 \\
\hline 2011 & 393 & 111 \\
\hline 2012 & 515 & 134 \\
\hline 2013 & 641 & \\
\hline
\end{tabular}

\section{Green Star in the literature}

The 'Australian Architecture Database' includes 43 published case studies related to the Green Star rating system from 2002 to 2013. Table 3 shows the number of publications with Green star projects based on their function and the number of stars they received.

Table 3: Green Star certified projects based on "Australian Architecture Database”

\begin{tabular}{|c|c|c|c|c|}
\hline Project's Function & 4 Star & 5 Star & 6 Star & Total number of projects \\
\hline Commercial building & 1 & 13 & 16 & 30 \\
\hline Educational building & 0 & 4 & 1 & 5 \\
\hline Childcare centre & 0 & 1 & 0 & 1 \\
\hline Convention Centre & 0 & 0 & 2 & 3 \\
\hline Heritage building & 0 & 2 & 1 & 1 \\
\hline Police station and court & 0 & 1 & 0 & 43 \\
\hline Shopping Centre & 1 & 0 & 0 & 2 \\
\hline Total & 2 & 21 & 20 & \\
\hline
\end{tabular}

Of all these case study articles, 19 were about 6-star Green Star office buildings and 21 were about 5- star buildings, while only 2 articles were about 4 star buildings. The fact that mostly 5- and 6- star buildings are reported on might suggest a bias in the literature towards reporting the most successful projects. This is in contrast to the 50 per cent of all registrations being 5 or 6 star buildings. All 43 of the papers indicated that the 
Green Star is an appropriate rating system.

\subsubsection{Living Building challenge (LBC)}

The Living Building Challenge was launched in 2006 with version 3.0 released in August 2014. It provides an outline for the design and construction, and the connection between people and the environment to accomplish the greenest stage of performance (International Living Future Institute, 2010). In contrast to the Green Star and other rating systems, LBC is more a way of achieving a sustainable solution rather than a strict rating tool. Full certification includes a requirement for the building to demonstrate net zero energy and net zero water performance over the first year of operation. The LBC introduces seven performance areas (denoted as petals) which are shown in Table 4.

Table 4: Seven petals of the LBC (International Living Future Institute, 2010)

\begin{tabular}{|c|c|}
\hline Petals & Imperatives \\
\hline \multirow{4}{*}{ Site } & Limits to growth \\
\hline & Urban Agriculture \\
\hline & Habitat exchange \\
\hline & Car free living \\
\hline \multirow[t]{2}{*}{ Water } & Net Zero water \\
\hline & Ecological water flow \\
\hline Energy & Net Zero Energy \\
\hline \multirow{3}{*}{ Health } & Civilized environment \\
\hline & Healthy air \\
\hline & Biophilia \\
\hline \multirow{5}{*}{ Materials } & Red list \\
\hline & Embodied carbon footprint \\
\hline & Responsible industry \\
\hline & Appropriate sourcing \\
\hline & Conservation + reuse \\
\hline \multirow{3}{*}{ Equity } & Human scale + human places \\
\hline & Democracy + social justice \\
\hline & Rights to nature \\
\hline \multirow[t]{2}{*}{ Beauty } & Beauty + spirit \\
\hline & Inspiration + education \\
\hline
\end{tabular}

There are three different types of certification for the LBC: 
1. Living Building Challenge certification covering all seven aspects.

2. Petal recognition: Achieving 'Petal' recognition means reaching three category requirements where at least one must be water, energy, and/or materials.

3. Net Zero Energy building certification.

By 2016, only eight buildings had achieved full LBC certification. A further six have Petal certification and 14 are Net Zero Energy. These are mostly located in the USA and Canada (International Living Future Institute, 2010). The SBRC at the University of Wollongong is the LBC certified building in Australia.

\subsection{Challenges associated with constructing sustainable buildings}

The majority of published papers found in the above-mentioned literature (Coimbra \& Almeida, 2013; Baird \& Field, 2013; Garzone, 2006; Kimber, 2012) and from the Australian Architectural Database show the benefits of constructing sustainable buildings. However, it is necessary to identify the challenges and difficulties involved in constructing them. There is a startling gap in the literature in relation to the difficulties in delivering Green Star or other ecologically sustainable projects.

Alnaser \& Flanagan (2007) discussed the challenges and difficulties of constructing sustainable buildings in the Kingdom of Bahrain. They identify the most important factor which discourages architects, policy makers, contractors, and users are the lack of information available about the benefits of constructing sustainable buildings. The solution is to get information to the public and train architects and contractors.

Another challenge was shown in the literature was difficulty in sustainable building design as a key for successfully delivering sustainable building (Edwards \& Hyett, 2005; Stanton, 2006). Edwards \& Hyett (2005) mentioned that the main factor for construction a sustainable building is to consider it in the early stage of design. The reason for fail in managing design is mostly because the building design process has become more complex over the years and also increasing the popularity of procurement routes (Beard et al. 1998; Gray \& Hughes, 2001; Bibby et al., 2003; Tzortzopoulos \& Cooper, 2007). Therefore certain qualifications are necessary for beneficial design management such as leadership, communication, teamwork, design procurement (Mills \& Glass 2009).

\section{Methodology}

This research seeks to discover the benefits and challenges to delivering sustainable building projects. While the benefits are well reported in the literature, there is a lack of published information about the difficulties and 
challenges for implementing such projects. In order to examine the reality of creating high performing sustainable buildings, the present research includes a number of case studies in various stages of completion. This has enabled the authors to interview the key people involved and discuss the real-world difficulties.

Therefore this research consists of:

- $\quad$ Case studies from the literature

- One completed project which gives access to a number of active participants

- One live project which gives access to a large number of stakeholders

\section{Results and discussion}

\subsection{The SMART Infrastructure Facility and Sustainable Buildings Research Centre (SBRC)}

This section presents the findings from two first-hand case studies: the SMART Infrastructure Facility and the Sustainable Buildings Research Centre (SBRC) at the University of Wollongong. The SMART building was designed to be a Four Star Green Star building. The SBRC project was designed to be a Six Star Green Star building and also to be Living Building Challenge certified.

These two buildings were chosen as case studies because the SBRC project was the highest level of sustainable building ever attempted by the University of Wollongong while the SMART is a typical university building aiming to be reasonably sustainable. The SMART building has been in operation since February 2011 while the SBRC project was in its construction phase at the time of this research and was initially occupied in mid-2013. They are accessible projects that provide the opportunity to examine the challenges and difficulties involved in delivering sustainable buildings. The research has been done through semi-structured interviews with the key stakeholders involved in these projects.

The SMART building had already been occupied, so most interviewees were members of UOW staff, including end-users such as the senior manager. It was not possible to contact the contractors, the estimator or certain other groups involved in the project because they were no longer available. For this reason, the SBRC building, which was in the final stages of the construction, was included in order to give the authors access to the whole delivery team as well as the some end users.

Table 5 lists the interviewees for the SMART and the SBRC buildings. Interviews were carried out according to UOW HREC Ethics Approval (Ethics Number: HE12/020). The semi-structured interviews were conducted in 
2013 and consisted of a set of questions to lead the conversation as shown in Table 6. Interviews were summarised and sent to interviewees for approval.

Table 5: Interviewees for the SMART Infrastructure Facility and the SBRC

\begin{tabular}{|l|c|c|}
\hline Interviewee's role & SMART & $\checkmark$ \\
\hline Director & $\times$ & $\checkmark$ \\
\hline Project manager & $\checkmark$ & $\times$ \\
\hline Senior manager & $\checkmark$ & $\checkmark$ \\
\hline Laboratory manager & $\times$ & $\checkmark$ \\
\hline Academic staff & $\times$ & $\checkmark$ \\
\hline Builder contractor & $\times$ & $\checkmark$ \\
\hline Cost planner & $\times$ & $\checkmark$ \\
\hline Structural engineer & $\times$ & $\checkmark$ \\
\hline ESD consultant & $\times$ & $\times$ \\
\hline IT manager & $\checkmark$ & $\times$ \\
\hline Chief operating officer & $\checkmark$ & $\checkmark$ \\
\hline Engineering operation manager & & \\
\hline
\end{tabular}

Table 6: Interview questions

\begin{tabular}{|l|cl|}
\hline \multirow{2}{*}{ Role } & - & What was your role in the project? \\
& - & When did you start to be part of this project? \\
& - & How did you start to be part of this project? \\
& - & What is your Vision of the SBRC/SMART Infrastructure Facility? \\
Vision & - & What was your strategy to achieve the main aims of this project? \\
& - & What were the main challenges? \\
Green & - & How much did you achieve the main view? \\
Star/LBC & - & Do you think this is successful project? \\
& - & What were the difficulties involved in achieving the Green Star/LBC? \\
\hline Advice & - & What would you do differently if you wanted to start this project again? \\
& - & Do you have any advice for other people who are interested in constructing this kind of \\
\end{tabular}




\subsubsection{SMART Infrastructure Facility}

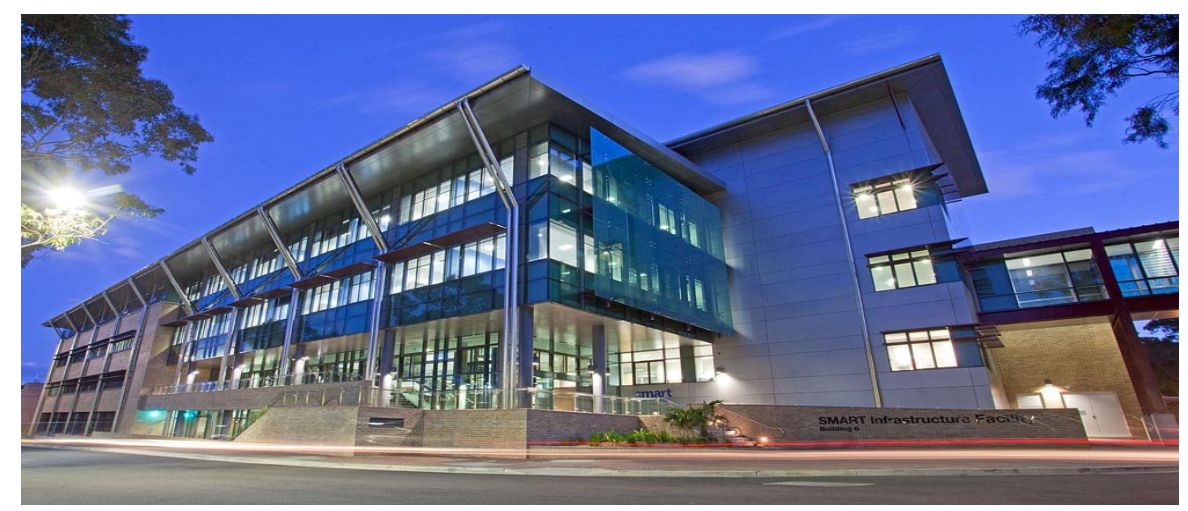

Figure 2: The SMART Infrastructure Facility (SMART Infrastructure Facility 2013)

The SMART Infrastructure Facility was the first building registered on the University of Wollongong main campus to be assessed for Green Building Council accreditation. It was assessed using the Green Star Education rating tool. At the time of writing, the building was currently in the final stages of documentation for Green Star certification and is expected to get a 4 Star Green Star rating. The SMART building is a four-story building of $12,000 \mathrm{~m}^{2}$. It is a research centre, which includes 30 specialist research and education laboratories (CUNDALL, 2011b). The first author is one of the occupants while the second author is a user of the teaching laboratories.

\subsection{Sustainability Vision of the SMART Infrastructure Facility}

Green Star was not considered in the initial design of the building. The vision for sustainability came during construction, from a senior University manager who wanted to promote Green Star ratings within the university. The architect indicated that it was impossible to achieve a Six Star Green Star with the available budget and the footprint of the building. The main aim was to construct the building as quickly as possible and then minimise the energy usage consistent with the budget and finally, see how many Green Stars could be achieved.

\subsubsection{Time and cost for the SMART Infrastructure Facility}

The building was completed to a budget of AUD $\$ 40.5 \mathrm{M}$ (including construction costs, consultancies, fees, furniture and user relocation). The construction cost of the building was $\$ 2610$ per square metre. The original schedule was to finish the project in October 2010 but final completion was achieved only in February 2011. This was deemed to be reasonable, given the scale of the project. This delivery date meant the building was operational in time for the first semester of the Australian academic year in 2011. Delays were caused mainly by weather and by one sub-contractor having solvency issues. 


\subsection{Delivering sustainability aspects of the SMART Infrastructure Facility}

The vision of SMART was to construct a reasonably sustainable building within a tight budget and time frame. To improve the sustainability of the building, there is extensive use of natural ventilation with a mixed mode HVAC system. In addition, natural light is used in all offices and laboratories and this provides impressive ocean and escarpment views (Mourtos, 2012). The lighting system for the corridors, offices, and laboratories is low brightness fluorescent luminaires with high efficiency. The lighting systems for meeting rooms and resources rooms have occupancy sensors which automatically turn lights off after 20 minutes of inactivity (Mourtos, 2012). Rainwater harvesting captures water from the roof for use in washrooms and for landscape watering and water supply to the fluids laboratory storage tank (130,000 litres capacity).

\section{Use of recycled materials in concrete}

The cement in the concrete used in the construction contained industrial waste product at a rate of $30 \%$ for in situ concrete, $20 \%$ in pre-cast concrete, and $15 \%$ in pre-stressed concrete. In addition, a further $20 \%$ of all the aggregate used for structural purposes was either slag or recycled aggregate. No natural aggregates were used for non-structural uses (e.g. building base course, sub-grade to any car parks and footpaths, backfilling to service trenches, kerb and gutter). Incorporation of a suitable proportion of either $10 \mathrm{~mm}$ or $20 \mathrm{~mm}$ slag aggregate in some of the mixes was used to reduce the amount of natural aggregate used (Portella \& Van Koverden, 2012).

Most furniture in the building is green rated and has certification for environmental qualities such as being environmentally innovative, reusable, containing eco-preferred materials, being durable, and being designed for disassembly.

\subsubsection{Challenges for the SMART Infrastructure Facility}

Achieving a Green Star rating presented some challenges. One was the additional capital cost for natural heating and cooling in the building. While this saves money during operation, it had an impact on the fixed budget. Another challenge was the use of a mixed mode of air conditioning. It was difficult for some users to accept not having air conditioning on all the time. This meant that in some respects, obtaining a balance between achieving the Green Star points and constructing a user-friendly building has been difficult. Another problem was the need to purchase Australian products in so far as possible. This added to the cost in the case of steel, which was purchased from the Australian supplier, BlueScope, although it was a mixture of Australian and Chinese product. 
The project manager and the chief operating officer considered that time and budget limitations for the building construction were the main challenges. It was essential to complete the building in time for the start of the teaching semester in 2011. The building had to open one month before classes began.

\subsubsection{Lessons learnt from the SMART Infrastructure Facility}

All the interviewees believed it was a successful project. It was close to being on time and within budget. The building is energy efficient and comfortable for the users. Like most projects, there are, however, some aspects that could be improved.

\section{- Green Star Certification}

Green star certification was not considered in the initial design. The final result for the SMART was expected to be between four and five stars. As this was the client's first building with a Green Star target, however, there was a lack of information about the Green Star rating and what features would impact upon the final result. The size of the building and key aspects of its design meant that it could not achieve five star rating.

\section{- Contract method}

The cost-plus contract was a challenge because there was a risk that the building would be over budget. Extra efforts were employed for cost control. Although it would have been more efficient to use a fixed price contract to ensure an affordable cost, this was not possible for the SMART because the funding arrangements meant that the project had to be finished quickly and construction started before the design was finished. This method posed a risk to the client because the ultimate cost of the building could not be known until it was completed.

\section{- Building operation and occupier satisfaction}

The chief operating officer believes the location of the staircases and lifts discourages users from using the staircase. This has a negative effect on occupier fitness and the energy efficiency of the building. Occupiers have complained that the natural ventilation louvres work automatically so the users cannot open or close the windows when they desire. Occupiers of offices situated next to the lift and the kitchen have complained about noise levels.

\subsubsection{Findings from the SMART Infrastructure Facility}

The interviewees had differing ideas for improving the project and ensuring the best results. These can be seen in Table 7. 
The key vision for SMART was to construct a reasonably sustainable building. This shifted to become a sustainable building with a Green Star rating. Since the Green Star concept was an afterthought, it did not affect the cost and timeline of the project and the results from interviews show that the aim was achieved. The interviewees were not totally in favour of aiming for a Green Star rating but they did favour sustainability. Some participants believed that the documentation required for a Green Star was tedious and costly and suggested it might not be used for future projects. However, the senior manager believed Green Star was necessary and that it was desirable to go for a six star target for some future projects. A common theme in the advice from the interviewees was to recognise the importance of consultation with all the stakeholders throughout design and construction. Even though there was extensive consultation, it appears that more could have been done.

Limitations in accessing certain key members of the SMART design and delivery team mean that the above data is somewhat incomplete. It would have been desirable to interview the design team and others involved in the project, but these individuals had moved on to other projects. The SBRC project is a building in progress, so the design team, contractor and project manager were still available. This helped with the acquisition of more data which could then be compared with the results from SMART.

Table 7: Advice from the SMART Infrastructure Facility's interviewees

\begin{tabular}{|c|c|}
\hline Role & Advice \\
\hline Project manager & $\begin{array}{l}\text { Keep everybody in the user groups informed about what is going on because there were three } \\
\text { academic user groups: Engineering, Informatics and Science and it is important to keep them } \\
\text { happy. }\end{array}$ \\
\hline $\begin{array}{l}\text { Engineering } \\
\text { operation } \\
\text { manager }\end{array}$ & $\begin{array}{l}\text { Involve technical staff in the design of the building to ensure the building is used more } \\
\text { efficiently and the laboratories and workshops are practical. } \\
\text { The team members need to be engaged in the user group meetings. }\end{array}$ \\
\hline $\begin{array}{l}\text { Chief operating } \\
\text { officer }\end{array}$ & $\begin{array}{l}\text { Have a practical eye for improvements along the way. } \\
\text { Consider the users and customers at different stages of construction. }\end{array}$ \\
\hline Senior manager & $\begin{array}{l}\text { Get more information on how to achieve Green Star rating. It is essential to understand how } \\
\text { much effort is required to increase the Green Star rating because it is new area, unfamiliar } \\
\text { even for many of architects. The University needs some philosophy about the expenses, } \\
\text { square metres, function, and other aspects of achieving Green Star rating. }\end{array}$ \\
\hline $\begin{array}{l}\text { Laboratory } \\
\text { manager }\end{array}$ & $\begin{array}{l}\text { Consultation is the key to the projects; there was a lot consultation for the SMART building } \\
\text { project. It is so important to talk to stakeholders at different stage of the project to find out } \\
\text { their needs and bring them together. Without consultation the result would be an impractical } \\
\text { building }\end{array}$ \\
\hline
\end{tabular}




\subsection{The Sustainable Buildings Research Centre}

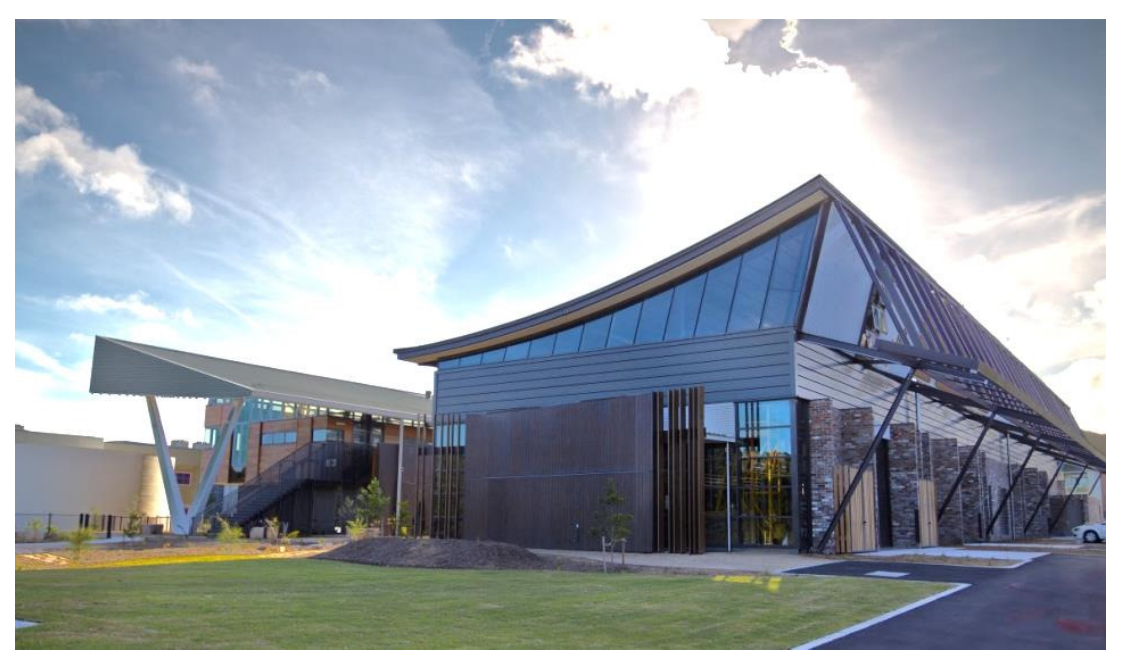

Figure 3: The SBRC building (Sustainable Buildings Research Centre, 2013)

The Sustainable Buildings Research Centre was the first building in Australia to attempt to achieve both a Six Star Green Star Rating and a Living Building Challenge certificate. The SBRC building is $2600 \mathrm{~m}^{2}$ and the site is $8000 \mathrm{~m}^{2}$ and was completed in mid-2013 (Sustainable Buildings Research Centre, 2013). In contrast to the SMART building, the SBRC was intended to achieve the highest environmental sustainability ratings from its inception. The interviews reported below, with the participants listed in Table 8 , were conducted during the final stages of the construction and prior to completion.

The SBRC is a 'living laboratory' which will benefit the building industry as a result of sustainable building technologies and components being integrated throughout the building for research and testing purposes. The SBRC has a range of facilities:

- Large scale integrated component testing lab

- Electrical power quality, renewable generation and storage lab

- Water sustainability lab

- Thermal analysis and simulation lab

- Roof top testing lab

- Building performance and monitoring lab

- Sustainability training hall

- Collaborative partner space (Sustainable Buildings Research Centre, 2013) 


\subsubsection{Vision of the SBRC}

The SBRC director and the university project manager both shared the same vision for the building. They stated that the original vision set by the University of Wollongong was to be a 6 Star Green Star building and to significantly reduce energy consumption per $\mathrm{m}^{2}$ below current benchmarks. During initial design workshops, the Living Building Challenge (LBC) was identified as the world leading certification to aim for. The design team was asked to incorporate the requirements of the LBC as well as Green Star. An Ecologically Sustainable Design (ESD) consultant was employed very early in the project.

The director believed that this project would be unique because the research done in creating this building was an essential part of the overall aims of the SBRC research team. The aim was to take advantage of the building design in order to use it for research and to engage in research into the design of green building as well.

The ESD consultant stated that the vision of the SBRC project was to get as close as possible to being a restorative building that would have a net positive impact on the environment. Most buildings today have significant negative impacts and even current best-practice ESD is still far from being sustainable. LBC status was considered to be the world leading and an Australian first. The SBRC project was seen as being a means of raising awareness of restorative buildings and encourages other projects to achieve a similar performance.

The structural engineer was of the view that the SBRC will be the leader and a central hub for research into sustainable development in buildings and retrofitting by helping in the push towards targets of:

- ESD for all buildings (commercial and residential)

- $\quad$ Net Zero water and power usage

- Net Zero emissions for buildings over the life of the building

SBRC was seen as potentially being a centre for the community, for learning/education and the dissemination of knowledge to inspire others to follow in the same direction.

\subsubsection{Time and cost for the SBRC}

The unit rate of the building construction was \$5466AUD per square metre, including the roof top test area. The first scheduled finishing date was at the end of 2012. It then shifted to April 2013, and the final schedule date for completion was in August 2013 (Sustainable Buildings Research Centre, 2013). These delays were not attributed to the building's innovative design, but rather to contractual and legal issues. 


\subsubsection{Sustainability for the SBRC}

The initial vision for the SBRC was to achieve a Six Star Green Star rating and then the LBC was added at an early stage of the design. By achieving the Six Star Green Star certification, the SBRC is a world leader in sustainability while adding complexity to the project and by achieving LBC, is a net zero energy and a net zero water building. Rain water is used for toilets and irrigation and all grey and black water will be treated on site.

Achieving net zero energy needed a range of different solutions. Producing power on site by utilising solar, and wind power has its limitations. A reduction in consumption is achieved through natural ventilation wherever possible while a ground source heat pump and state-of-the-art low energy HVAC were added to the project. Electricity consumption is targeted throughout the building.

Green IT and lighting solutions are employed in the SBRC building. The IT solution is to employ a thin client solution to decrease the thermal load in the offices. By reducing the projected power consumption through green IT and other efficiency measures the required size of the PV systems was decreased to manageable proportions.

Achieving zero emissions was done by selecting low embodied energy materials and/or using recycled and environmentally friendly products such as low embodied emissions concrete floor slabs and reused brick walls. The reduction in the energy requirements of the building was not just a case of looking at the upfront cost; it included looking at the lifecycle cost. For concrete, less Portland cement and more recycled/reclaimed products such as aggregate substitution (20\%) was used, as was recycled slag or aggregate from demolished slabs and reclaimed unused fresh concrete was returned to its manufacturer i.e. an inadequate slump (CUNDALL, 2011a; CUNDALL, 2011b).

With regard to the LBC, the Equity and Beauty were the easiest petals to achieve because of the design of the building and its purpose. Achieving net zero energy and water was considered achievable though difficult. The greatest risk to achieving LBC certification was managing the materials and, in particular, avoiding 'Red List materials'. These are materials such as lead, PVC etc. that are held to be toxic or employ toxic chemicals in their manufacture. Glues must be formaldehyde free. In addition, the provenance of all materials used in construction must be verified through meticulous documentation. During the design, the risk to achieving a 4, 5 and 6 Green Star Rating was continually reviewed. By the start of construction, achieving 5 stars was considered certain and achieving 6, highly likely which was achieved. 


\subsubsection{Challenges for the SBRC}

Understanding the LBC benchmarks for sustainability was difficult for the architects and the rest of the team because, with this being the first LBC project in Australia, all participants lacked experience with this rating system. The design team had previous experience with 5 Star Green Star buildings but still found they had to rethink ideas to meet the $\mathrm{LBC}$.

Because the SBRC is a showcase for sustainability research and advanced technology, it was not just a conventional building project. SBRC consists of a further five sub-projects: furniture, fittings, Green IT, wind power, and photovoltaics, which are also challenges because they have different priorities and timeframes. These are interlinked with the building design and with the LBC and Green Star rating.

Because the LBC had never been attempted in Australia before, it contains many American references, standards and assumptions which are not appropriate in the Australian context. Australia is a big, sparsely populated country with limited manufacturing industries which makes finding locally sourced products that meet $\mathrm{LBC}$ requirements very difficult. This means that some materials could not be provided locally and needed to be obtained from elsewhere. This added to energy consumption. Supply chains are generally difficult to track and information regarding products and materials can be difficult to extract. Supply distances were negotiated with LBC for the Australian context.

The most difficult part of the process for the builder was the material petal of the LBC. This had not been done in Australia before and concepts such as the Red List of items were foreign. The need to document supply chains back to the source was a problem as many suppliers were not able to certify their sources. The logistics of recycling waste materials produced while constructing the SBRC for LBC was another challenge because materials needed to be placed in separate bins, such as timber, plastic, wood, and a general bin for general rubbish for recycling. This went beyond normal practice in Australia.

Achieving Net Zero energy has two different aspects: generating power and the energy usage of the equipment. Every kilowatt-hour of energy had to be estimated and balanced by an ability to generate renewable energy onsite. This was especially difficult considering the range of equipment needed in research laboratories.

Coordination between IT and constructing the building was always a challenge because construction would not stop for IT; so the IT system must fit into the timeline. There were one or two critical weeks at the end of the construction schedule where the IT equipment must operate the building management system for security and 
opening and shutting doors, so the building was not secure and completed until this equipment had been installed.

\subsubsection{Lessons learnt from the SBRC project}

The Project Manager stated that it is necessary to confirm how the vision for the project is to be delivered as early as possible (mentioned in the literature as well) and then to make sure that everybody involved in the project has a clear understanding of what the project is going to be. Therefore, the ESD consultant, the structural engineer, the mechanical engineer, the IT team, etc. must be engaged in the project very early on. In this way, problems can be predicted and resolved before the architect produces the drawings. This prevents the need for paying for continued editing of the drawings.

Another aspect which was mentioned by a number of interviewees was that the number of engineers and contractors capable of constructing highly sustainable buildings was limited. It is still difficult to meet the timelines when there is a lack of experience in the fine details. The project needs clear outcomes and goals from the ESD point of view to integrate the work and explain the process early on in the project. It is imperative that the outcomes and aims be reflected in the design consulting arrangement; otherwise, there will be problems. In addition, the Project Manager said that the design delivery for the SBRC project did not take enough time to deal with life cycle cost and maintenance because the maintenance group is different from the capital project group.

Achieving the material petal of the LBC was one of the most difficult aspects of this project. Therefore more thought and effort need to be put into materials at the beginning of LBC projects at the design stage. More feedback from industry should have been sought early in the design. Clients need to be given more feedback about the cost of the materials in order to achieve a high LBC rating.

\subsubsection{Advice from the SBRC's interviewees to improve sustainable projects}

It is important to develop LBC rules appropriate for Australia. These must follow the LBC guidelines and the principles of ESD and adapt through the approach of sustainability. As a showcase in sustainable research, the building of the SBRC is intended to become a vehicle to educate the participants in Green Star and LBC.

The project manager believed that dealing with the material petal of LBC should have been done at an early stage in order to guide the design team through the principles driving the design. Because achieving 6 Green 
Star rating and LBC was a great challenge, he advised that a thorough understanding of them should be gained as early as possible so that their principles can influence the design.

The cost planner thought we should be aware of two ways of being assessed for compliance with LBC and Green Star because they have similarities in terms of the sustainability but their method of assessment is completely different. Therefore, the solution would be to try to integrate Green Star and LBC because LBC only considers construction while Green Star looks at design and actual construction.

It is essential to acknowledge the additional cost of achieving Six Star Green Star and/or LBC ratings over the cost of a 5 star building. When the aim is 6 Star Green Star the building must demonstrate world leading sustainability characteristics. This level of innovation will require bespoke solutions. For LBC, achieving $100 \%$ Net Zero Energy rating requires significant investment in renewable energy and in low energy consumption appliances and equipment. Similarly, the Net Zero water requirement of LBC demands investment in equipment that is not needed in a 5 star building. The project promoter can make a conscious decision about these investments and the value of achieving LBC and/or 6 stars.

It is necessary to find professionals familiar with the LBC before commencing construction. There is a need for more builders who are familiar with LBC's material petal and its impact on price. The building contractor thought they should have been consulted up front in the design to make sure the estimated costs reflect what the building was actually going to cost. He also believed that providing a material tracking register where the architect can show how to achieve the LBC material petal is an efficient way of doing this.

\subsubsection{Findings from the SBRC building project}

The key vision for the SBRC was to construct a world-leading building by achieving the Six Star Green Star rating and also meeting the Living Building Challenge. There were many challenges and difficulties inherent in achieving this because it was the first time the team had attempted this. The most difficult challenge in the project was the material petal of LBC because it was a standard based on the American situation and industry, and was difficult to deliver in Australia. The best solution would be to adapt the LBC to Australia and deal with the material petal of the LBC at an early stage.

\section{Data analysis}

The literature review, SMART, and SBRC demonstrate the progress in constructing sustainable buildings. The only challenge covered in the literature review was the lack of knowledge of the architects and contractors. The main challenges for delivering sustainable buildings were addressed in the SMART and SBRC in Table 8. 
The SMART building cost nearly half of the SBRC project per square metre while the SBRC is net zero energy and net zero water. A large part of this additional cost for the SBRC was due to the extensive equipment incorporated in the building for research purposes as well as for its sustainability goals. For example, the extensive PV and PVT electricity generation and the ground source heat pumps/in-slab hydronic heating and cooling were incorporated in the SBRC building but not in the SMART building. It is necessary to recognise that part of the aim of the SBRC building was to act as a research facility while buildings, in general, do not need to be research and sustainability showcases.

A comparison of the challenges of the SMART and SBRC, listed in Table 8, shows that the SBRC project was more complex, and had more challenges in order to achieve a 6 Star Green Star and the LBC. The SBRC project had the delay due to the contractual and legal issue.

Table 8: Comparison of the challenges for the SMART Infrastructure Facility and the SBRC

\begin{tabular}{|l|c|c|}
\hline \multicolumn{1}{|c|}{ Challenges } & SMART & SBRC \\
\hline Additional cost for Green Star and/or LBC & $\checkmark$ & $\checkmark$ \\
\hline Time & $\checkmark$ & $\times$ \\
\hline Budget & $\checkmark$ & $\times$ \\
\hline Multiple users & $\checkmark$ & $\checkmark$ \\
\hline Site access & $\times$ & $\checkmark$ \\
\hline Dealing with novelty & $\times$ & $\checkmark$ \\
\hline Procurement & $\times$ & $\checkmark$ \\
\hline Balancing Green Star \& LBC & $\times$ & $\checkmark$ \\
\hline Adapting LBC & $\times$ & $\checkmark$ \\
\hline Materials selection & $\times$ & \\
\hline Net Zero Energy & & $\checkmark$ \\
\hline
\end{tabular}

The challenges for the SMART and the SBRC were different. The challenges for the SMART are related to its function as a multi-user building, site access, and obtaining documentation for Green Star after the event. The challenges for the SBRC were mostly related to the concept of sustainability, and achieving a 6 Star rating and meeting the LBC. This project has many levels of innovation and the design and delivery teams were not experienced in sustainability at this level, so it was difficult to deliver on the vision. Achieving the material petal of the LBC for selecting and sourcing the materials was the biggest challenge in the SBRC project. 
The results show that learning to construct sustainable building brings certain aspects of innovation because of doing the job for the first time. It seems that in order to be sustainable, it is essential to be innovative because sustainability is not fully embedded in the supply chain, and we do not have enough architects and contractors who are trained in this aspect. For a sustainability approach it might be useful to look at projects by people who have already constructed sustainable buildings. Subsequently it would be useful to look at the next building by these groups because they are experienced now. Buildings like SBRC are bringing new contractors with skills in sustainability to promote sustainability in society.

\section{Conclusions}

This paper has identified the challenges posed in the delivery of two sustainable buildings. Most of the published literature on sustainable building projects presents only positive or successful outcomes (Coimbra \& Almeida, 2013; Baird \& Field, 2013; Garzone, 2006; Kimber, 2012). There is very little coverage of the real difficulties experienced in delivering truly sustainable and innovative buildings (Alnaser \& Flanagan, 2007; Edwards \& Hyett, 2005; Stanton, 2006). This lack of coverage has been addressed by an examination of recorded and first hand, real, case studies. The use of green rating tools has been examined in some detail for the two first-hand case studies. Both SMART and the SBRC buildings focussed on innovation and sustainability. Another objective in the research was to find out the opinions of the delivery teams about their sustainable buildings and the green rating tools.

The results shown in Table 8 demonstrate that there were more challenges in achieving the 6 Star Green Star rating and meeting the LBC for the SBRC project than there were for SMART. Achieving a 6 Star Green Star rating means the building is an international leader in sustainability. Three out of eight interviewees had negative feelings about green ratings. They believed the system was too prescriptive, costly, and needed too much documentation. Project managers from both projects believed that Green Star made the projects difficult, achieving the points was sometimes tedious and time consuming. Those involved in the LBC were more positive but acknowledged that achieving this standard in Australia is difficult. Most of the difficulties were related to documentation and sourcing materials. The SBRC cost planner and the contractor preferred the Green Star system to the LBC.

As Alnaser \& Flanagan (2007) have pointed out, it is essential to have architects, designers and contractors who are well informed about sustainability and achieving green ratings. Even though the Green Star rating system 
has been in existence for over a decade, there is still a limited experience of it amongst construction professionals in regional Australia. This is improving slowly.

The rate of new registrations for Green Star has dropped in the last couple of years. The Living Building Challenge is still a very new sustainability index with version 3.0 being published in 2014 . At the time of writing, two new buildings registered by LBC opened, one building commenced construction and four new buildings registered in Australia (Gray \& Hughes, 2001). LBC is seen by most practitioners as more demanding than Green Star, but with a more holistic philosophy. Building projects such as SBRC help to educate more professionals in advanced ecologically sustainable development.

Rating systems help people who are new to constructing sustainable buildings. A number of interviewees indicated that they would continue to build highly sustainable buildings but not always use restrictive rating tools which require extensive documentation that does not always deliver value. It is more important to understand the philosophy of ecological sustainability and implement it in a holistic and cost effective way that to merely achieve rating points.

ACKNOWLEDGEMENT: The authors wish to gratefully acknowledge the help of design and delivery team of the SMART Infrastructure Facility and the SBRC and Dr. Madeleine Strong Cincotta in the final language editing of this paper.

\section{REFERENCES}

Alnaser, N.W. and Flanagan, R., 2007. The need of sustainable buildings construction in the Kingdom of Bahrain. Building and Environment, 42(1), pp.495-506.

Baird, G. and Field, C., 2013. Thermal comfort conditions in sustainable buildings-Results of a worldwide survey of users' perceptions. Renewable Energy, 49, pp.44-47.

Beard, J., Loulakis, E.M. and Wundram, E., 2001. Design-build: Planning through development. McGraw Hill Professional.

Bibby, L., Austin, S.A. and Bouchlaghem, N.M., 2003. Defining an improvement plan to address design management practices within a UK construction company. International journal of IT in Architecture, Engineering and Construction, pp. 57-66.

Bremner, C., Caplan, R., Hepburn, C., Heller, T., Keogh, M., Mostyn, S., Nicholson, T., AO, A., Waller, M., Westacott, J., Williams, B. and Wonhas, A., 2010. Low Carbon Growth Plan for Australia, Climate Works Australia.

Brundtland, G., 1987. Our Common Future, United Nations General Assembly, New York. 
Coimbra, J. and Almeida, M., 2013. Challenges and benefits of building sustainable cooperative housing. Building and Environment, 62, pp.9-17.

CUNDALL, 2011a. Risk Review of Targeting a Living Building Challenge Rating, University of Wollongong SBRC.

CUNDALL, 2011b. Risk Review of Current Green Star Strategy, University of Wollongong SBRC.

Edwards, B and Hyett, P., 2005. Rough guide to sustainability, 2nd edn, London.

Garzone, C., 2006. Us green building council and the LEEDTM green building rating system.

Gray, C. and Hughes, W., 2001. Building design management. Routledge.

Green Building Council of Australia, 2014. Green Building Council of Australia, < http://www.gbca.org.au/ >

Green Building Council of Australia, 2013. The value of Green Star- A decade of environmental benefits, < https://www.gbca.org.au/uploads/194/34754/The_Value_of_Green_Star_A_Decade_of_Environmental _Benefits.pdf $>$.

Haapio, A. and Viitaniemi, P., 2008. Environmental effect of structural solutions and building materials to a building. Environmental Impact Assessment Review, 28(8), pp.587-600.

International Living Future Institute, 2013. Annual report 2013, < https://livingfuture.org/sites/default/files/reports/ILFI\%202013\%20Annual\%20Report_sm_pages.pdf $>$.

International Living Future Institute, 2010. Living Building Challenge 2.0. International Living Building Institute.

Kibert, C.J., 2012. Sustainable construction: green building design and delivery. John Wiley \& Sons.

Mills, F.T. and Glass, J., 2009. The construction design manager's role in delivering sustainable buildings. Architectural Engineering and Design Management, 5(1-2), pp.75-90.

Mourtos, P., 2012. Draft welcome to SMART Infrastructure Facility. Wollongong: University of Wollongong, pp. 1-34.

Nguyen, B.K. and Altan, H., 2011. Comparative review of five sustainable rating systems. Procedia Engineering, 21, pp.376-386.

Portella, J. and Van Koeverden, M., 2012. SMART Infrastructure building project, Wollongong UniversityGreen Star concrete credit assessment, concrete technologist report, Sydney: Engineered Material Solutions.

Romilly, M., 2012. A decade of green building 2002-2012, Green Building Council Australia, < http://www.gbca.org.au/uploads/170/34474/A_decade_of_green_building_pdf $>$.

Scheuer, C., Keoleian, G.A. and Reppe, P., 2003. Life cycle energy and environmental performance of a new university building: modeling challenges and design implications. Energy and buildings, 35(10), pp.1049-1064.

SMART Infrastructure Facility, 2013. SMART infrastructure Facility, University of Wollongong, < http://smart.uow.edu.au/about/index.html $>$.

Stanton, J., 2006. Get sustainable or lose out. Contract Journal, 434(6601), p.10.

Sustainable Buildings Research Centre, 2013. Sustainable Buildings Research Centre, University of Wollongong, < http://sbrc.uow.edu.au/sbrcbuilding/index.html $>$. 
The World Bank Group, 2014. $\mathrm{CO}_{2}$ emissions (metric tons per capita), < http://data.worldbank.org/indicator/EN.ATM.CO2E.PC $>$.

Tzortzopoulos, P. and Cooper, R., 2007. Design management from a contractor's perspective: The need for clarity. Architectural Engineering and Design Management, 3(1), pp.17-28.

Wilkinson, S.J., Remøy, H. and Langston, C., 2014. Sustainable building adaptation: innovations in decisionmaking. John Wiley \& Sons. 